\title{
Practice Collaborative Innovation and Promote Interdisciplinary Integration
}

\author{
Hai-Bo YANG ${ }^{*}$ Xu-Xia WANG, Ting-Ting LIU, Chao ZHANG, Dong-Bai SUN \\ University of Science and Technology Beijing , Beijing 100083 \\ yhb@ustb.edu.cn \\ ${ }^{*}$ Corresponding author
}

Keywords: Collaborative innovation, Cross-disciplines, Social demand.

\begin{abstract}
Colleges and universities shoulder the responsibility for providing talents guarantee and intellectual support to socialist modernization construction, and carry out collaborative innovation and cross discipline are the important ways for universities to promote innovation ability and cultivate innovative talents. Based on the collaborative innovation, Interdisciplinary Center(IDC) was set up by University of Science and Technology Beijing(USTB). Interdisciplinary Center takes the major national demands for traction and conducts scientific research of cross-disciplines which contains materials, mechanics, mechanical, metallurgical and other subjects. The exploration and practice of the organization and operation of Interdisciplinary Center are valuable and significant for popularization.
\end{abstract}

\section{Introduction}

President Hu Jintao gave an important speech at Tsinghua University Centennial Celebration on April 24, 2011. He proposed to establish strategic alliances of collaborative innovation to promote resource sharing and to carry out major scientific projects together [1]. President $\mathrm{Hu}$ pointed out that colleges and universities should actively adapt to the great demands for the development of economy and carry on some researches, including the strategic research of the urgent need for country, the prospective study of the frontiers of science and technology, the public welfare research concerning the major issues of national economy and the people's livelihood. From the history of scientific development we can see that most of major breakthroughs in cutting-edge science and major original scientific research achievements come from interdisciplinary integration [2]. The collaborative innovation in colleges and universities is another major strategic deployment after 211 Project and 985 Project, proposed by The Party and The Country. It is an important measure to advance the development of higher education in China healthily and sustainably. It has brought great opportunities and challenges for colleges and universities to reform the system of comprehensive education [3].

In this context, taking material science, mechanics, mechanical, metallurgical and other disciplines as the foundation, USTB carried out a series of exploration and practice in the establishment of cross discipline and acquired some achievements. All of these have the important value for the similar institutions to reference.

\section{Collaborative Innovation and Cross Discipline}

Collaborative innovation refers to an effective convergence of innovation resources and elements. For realizing the deep cooperation, innovation subjects break through the barriers between each other and fully release "talent, capital, information, technology and other elements of innovation activity". Interdiscipline is a fusion of discipline which based on two or more single discipline and formed by different disciplines, departments and branches. They interrelate, interacte and interpenetrate with each other ${ }^{[2]}$. The key of promoting the development of collaborative innovation lies in promoting the closely docking and deep cooperation among colleges and universities, research institutes and enterprises, forming the situation of "complementary advantages, resource sharing, mutual reciprocity and mutual benefit, common development". However, the development of interdiscipline cannot do without the practice of scientific research. Combination of industry-university-research provided a broad space for the 
development of collaborative innovation and interdiscipline. Advanced technology in enterprise involves more disciplines than one, in other word, it is the product of the development of multi-disciplinary cross. Combination of industry-university-research to the benefit of promoting the development of the discipline, knowledge innovation and graduate students innovation training. Thus, it is an important way to promote interdiscipline construction for achieving a breakthrough in technological innovation and cultivating innovative talents.

\section{The Importance of Interdiscipline Construction}

Colleges and universities shoulder the responsibility for providing talents guarantee and intellectual support to socialist modernization construction. Taking the major national demands for traction, the construction of cross discipline is beneficial for colleges and universities to enhance the overall research capacity. Therefore, it has become one of the most important goals for colleges and universities to improve collaborative innovation and discipline construction, and it is of great significance.

(i) The objective needs of social development

Issues society faced becomes increasingly complicated, so that the single discipline has been not enough. In order to solve complex major social issues, we need interdisciplinary integration, using the advantages of group brainstorming to solve problems. Therefore, in order to meet the objective requirements of social development and promote social progress, for universities, discipline research is very urgent to develop and compound talents with broad knowledge, strong operational capacity, high-quality need to be cultivated. And then "1+1> 2" nonlinear effects can be achieved $\left.{ }^{4}\right]$.

(ii) The inevitable trend of science development

With the development of modern science and technology, the depth and breadth of scientific research continue to expand, and the degree of integration is more prominent. Spark generated by interpenetration and collision between disciplines is one of the driving forces of scientific development, and it is also a source of point with many innovative, it is the driving force of disciplines development. Therefore, for grasping the forefront of scientific development and continuing to broaden the field of scientific research, great attention must be paid to the study of cross-disciplines. Cross-disciplines is the inevitable trend of the development of science and technology.

(iii) An important way to cultivate innovative talents

With the competition of comprehensive national strength is becoming increasingly fierce, the cultivation of high level creative talents has become the focus of international competition. Colleges and universities should take positive interaction of personnel training and scientific research. Collaborative innovation is an important channel to build universities with the world class and high level, while, interdisciplinary integration is a key way to cultivate innovative talents in universities. It is helpful for broadening the students' knowledge and strengthening the students' comprehensive ability to set up interdisciplinary and establish interdisciplinary research center. In the process of developing collaborative innovation, high level science and technology innovation platform can be built and multiple collaborative innovation training mode can be explored. So it laid the wide foundation for the cultivadation of innovative talents [5].

\section{Establishment of Interdisciplinary Centre}

Based on the advantage of subject resource, including material, mechanics, mechanical, metallurgical and other cross disciplinary, Interdisciplinary Center of USTB was set up. With a background of great demand of our materials technology development and national defense construction, Interdisciplinary Center focus to the research of new materials, functional materials, innovation technology of material security service and other relevant scientific problems.

(i) The construction of innovative teams

Interdisciplinary Center organized a research team of multi-disciplinary and cross college. It consists of forty researchers, including professors, associate professors, $\mathrm{PhD}$ graduates and master of the laboratory. All of them work together to carry out scientific and technology researches. Multiple disciplines include materials science and engineering, power engineering and engineering thermal physics, mechanical 
engineering, metallurgical engineering, continuum mechanics, condensed state physics, computer science and technology, measurement technology and instrumentation, control science and engineering etc. Because of different areas and different problems, the thinking of researchers will need continuously change and innovate, and the knowledge and information are in continuous absorption, application and renewal.

(ii) To carry out the scientific researches

Since 2009, Interdisciplinary Center has undertaken a number of major scientific and technological tasks from the relevant ministries and commissions of the state, including XX Basic Research Project, XX Engineering Projects of Fixed Assets Investment, XX Project 'Twelfth Five-year' Plan Project. In addition, Interdisciplinary Center also assumed National Key Scientific Instrument and Equipment Development Project, which is one of 53 special projects organized by Ministry of Science and Technology. Scientific researches of Interdisciplinary Center include basic research and applied basic research of high-temperature materials component, thermal protection materials, lower heat insulation materials and structures, sealed connectors, multivariate and multiscale simulation analysis of coupled thermo-hydro-mechanical processes under hypersonic environment, extreme environmental test and measurement technology and so on. According to the national defense needs, other important research orientation will be developed gradually. In addition, in order to ensure the successful completion of the project, seminars were organized regularly to make summarizes and do progress reports. For enhancing research capacity, researchers were organized to participate in academic exchanges and visited to relevant units. During communication, good cooperative relationships have been set up in terms of project cooperation and talent cultivation, and long-term cooperation mechanism has been established.

(iii) Achievements

The education model of industry-university-research cooperation is an important way to cultivate high-quality research and application-oriented talents. According to the needs of aerospace materials, Interdisciplinary Center integrated with industry. It got innovation from traditional metallurgical technology and upgraded original equipment. As a result, new technical principle to come into being, and it has its own characteristics and advantages and can be used for aerospace materials testing. This work got recognition and support by relevant user units.

In terms of personnel training, according to the need of collaborative innovation, different academic teams communicate with each other. They actively look for an entry point of interdisciplinary integration and break barriers between faculties and disciplines, and then work together to carry out scientific and technology research. Consequently, a group of young teachers have been built up, a batch of $\mathrm{PhD}$ and postgraduates with rich practical experience and ability of analyzing and solving problems independently have been trained.

In terms of construction and development of discipline, upholding the principle of demand traction, Interdisciplinary Center established subject groups of materials, metallurgy, machinery, testing, information and other multi-discipline for supporting personnel training and research needs in the field of materials science. At present, Interdisciplinary Center has achieved multidisciplinary integration, promoted the development of related disciplines, formed a group of characteristics disciplines and a development mechanism with interdisciplinary mutual promotion and fusion.

\section{Conclusion}

Collaborative innovation has brought opportunity for universities to enhance the innovation capacity. It requires colleges and universities to achieve development of discipline, technology and talent through multilateral coordination. Based on the work completed in prophase, Interdisciplinary Center of USTB will integrate various kinds of superior resources in schools and beyond further, and enhance the depth and breadth of interdisciplinary. Around the major demands of scientific and technological task and the direction of technology development, Interdisciplinary Center will make the cultivation of innovative ability, practical ability and other key capacity as the main line, to build a high quality innovative team of science and technology with stable scale and reasonable structure. In the end, the cross fusion of materials, metallurgy mechanical, electrical, testing, information science and engineering will come true, the disconnection between the various disciplines will be broke, and the gaps between each subject fringe will 
be filled. And then a new frontier will be gave the birth, which will make a greater contribution to build our country into a technological power and human power.

\section{Acknowledgment}

This work has been performed with the financial supports of National Key Scientific Instruments and Equipment Development Special Fund (2011 YQ140145).

\section{References}

[1] $\mathrm{Hu}$ Jintao, Speech at the Meeting of Tsinghua University Centennial Celebration[N], Daily, 2011-04-25(1).

[2] Liu Yurong, Zhang, Exploration and Practice of Interdisciplinary Research[J], Value engineering, 2013 (11):231-232.

[3] Jiang Yanping, Theory and Practice Analysis of Collaborative Innovation in Universities[J], Technology Management Research, 2013 (18):23-26.

[4] Chen Jin, Collaborative Innovation and National Research Capacity Building[J], Scientific Research, 2011, (12):1762-1763.

[5] Wang Shuguo, Vigorously Promote Collaborative Innovation to Improve the Quality of Personnel Training[J], University (Academic Edition), 2013 (6):43-47. 